\title{
Interpret Cross-cultural Elements in The Wedding Banquet Based on Culture Dimension and High Context and Low Context and the Theory of Time Orientation
}

\author{
Yuan He \\ School of Foreign Languages, East China University of Science and Technology, Shanghai, China \\ Email: hydaisy137@163.com
}

How to cite this paper: He, Y. (2020) Interpret Cross-cultural Elements in The Wedding Banquet Based on Culture Dimension and High Context and Low Context and the Theory of Time Orientation. Open Access Library Journal, 7: e6772. https://doi.org/10.4236/oalib.1106772

Received: September 2, 2020

Accepted: September 26, 2020

Published: September 29, 2020

Copyright $\odot 2020$ by author(s) and Open Access Library Inc.

This work is licensed under the Creative Commons Attribution International License (CC BY 4.0).

http://creativecommons.org/licenses/by/4.0/

\section{(c) (i) Open Access}

\begin{abstract}
Hofstede, a renowned Dutch scholar, puts forward a concept called "culture dimension" in Culture's Consequences. Four aspects are included in the concept: power distance, uncertainty avoidance, individualism and collectivism, masculinity and femininity. American anthropologist Edward Twitchell Hall advances high context and low context to analyse cultural diversity based on the two concepts. Professor Kluckhohn from Harvard University and Strodtbeck put forward the theory of time orientation. The Wedding Banquet is directed by the famous director $\mathrm{Li}$ An, presenting a story about an Asian-American whose name is Gao Weitong. He is a homosexual, choosing to marry a female painter who is an illegal immigrant in order to deal with his parents from Taipei to force him into marriage. The thesis will choose two aspects of "culture dimension" (power distance and uncertainty avoidance), high context and low context, and the theory of time orientation to analyse cross-cultural elements in The Wedding Banquet.
\end{abstract}

\section{Subject Areas}

Culture

\section{Keywords}

Culture Dimension, High Context, Low Context, Time Orientation

\section{1. 引言}

霍夫斯塔德是荷兰社会人文学博士和著名学者, 他在调查了 IBM 公司来 
自 70 多个国家一共约 117,000 员工的工作价值的基础上, 写出了非常著名的 《文化的结局》(Culture's Consequences)一书, 书中提出了“文化维度”(Culture Dimension)这一概念。所谓 “文化维度” , 就是 “一种文化相对于其他文化 来说可以测量的方面” [1]。霍夫斯塔德提出的文化维度一共包括四个方面: 权力距离、不确定性规避、个人主义与集体主义, 男性气质和女性气质。后 来他又增加了 2 个文化维度, 分别是长期导向与短期导向以及放纵与约束。 美国人类学家 Edward Twitchell Hal 在 Beyond Culture 中提出高语境与低语 境, 并根据两者的不同来分析文化的多样性。美国人类学家、哈佛大学教授 克拉克洪(Kluckhohn)和 Strodtbeck(斯托特贝克)提出六大价值取向理论, 其 中之一便是时间取向理论。

《喜宴》这部电影由著名导演李安拍摄, 讲述了定居在美国的同性恋者 高伟同, 为了打发从台北而来逼婚的父母, 与因为拿不到美国绿卡发愁的非 法移民女画家顾威威假结婚, 而展开的一连串故事。影片中的高伟同高大英 俊, 事业有成, 在纽约有一个美国男友赛门, 两人在一起幸福地生活。但是 远在中国台湾的父母并不知道高伟同的性取向, 一心希望自己的独子能够早 点结婚, 为高家延续子嗣。高伟同为了打发父母, 便上演了一出假结婚的戏 码, 结果却一波三折。本文将选取霍夫斯塔德文化维度理论的两个方面, 即 权力距离和不确定性规避, 以及高语境与低语境和时间取向理论来分析《喜 宴》这部电影中的跨文化元素。

\section{2. 权力距离}

霍夫斯塔德对权力距离是这样定义: “在一个国家的社会群体或组织机 构内拥有较少权力的社会成员对权力分配不均的可接受程度” [2]。这里的 “社 会群体” 指得是一些基本社会单位, 比如家庭、学校和社区等。组织机构一 般指的是人们工作的场所。权力距离大的文化成员视权力为社会的基本因素, 强调强制力和指示性权力。与之相反, 在权力距离小的社会单位及组织机构 中, 等级观念较弱, 人们倾向于认为人人平等, 即使下属有和上级有不一样 的想法和观念, 也可以直接提出来。儒家思想是中国传统文化的核心, 它的 道德伦理思想有鲜明的等级性, 并要求和维持人际关系的次序和等级, 如 “君 为臣纲、父为子纲、夫为妻纲” 的三纲以及 “父子有亲、君臣有义、夫妇有 别、长幼有序、朋友有信” 的五伦。除此之外, 以研究中西方文化比较见长 的钱穆先生认为 “中华文明是典型的农业文明” [3], 农业文明的最显著特征 是宗法制, 宗法指得是以家族体系组成并崇拜祖先的社会, 人们靠宗法的力 量维持一定的秩序。虽然现在宗法制已不复存在, 但是却依然植根于农耕文 化中。所以，中国是非常典型的权力距离大的国家。

在《喜宴》这部影片中, 权力距离大这一文化维度有明显的体现。高伟 同的父亲是当年撤退到台湾的国民党军队的师长, 到纽约探望儿子时, 高伟 同带他到当地一家最好的中餐馆吃饭。碰巧的是, 餐馆老板老陈碰巧是高伟 同父亲当年的部下。高伟同父亲在异乡碰到故人非常开心, 让老板和自己坐 到一起吃饭。餐馆老板连忙拒绝, 说到 “师长, 太太, 您别折腾死我老陈了。 有您们两位在, 我怎么敢坐啊!” 并且依然毕恭毕敬地称高伟同的父亲为 “师 
长” 和高伟同为 “大少爷” 。除此之外, 高伟同和顾威威假结婚, 举办中式 婚礼的当天, 他们俩都要向高伟同的父母下趾, 以示尊重。而高伟同在结婚 的前一天, 也向自己的父母下跪, 感激父母对自己的养育之恩。高伟同的父 亲有晨练的习惯, 他陪父亲晨练时, 每次都会走在父亲的后面, 让父亲走在 前面。无论是时隔多年自己已经成为成功的中餐厅老板, 仍然尊称高伟同父 亲为 “师长” 的部下老陈, 还是向父母下跍以及让父亲走在前面的高伟同, 都 能看出他们对上司和长辈的敬畏, 以及中国文化中存在的权力距离大的现象。

\section{3. 不确定性规避}

“不确定性规避表示人们对未来不确定性的态度。对不确定性规避程度 较强的文化往往有明确的社会规则和原则来指导几乎所有情况下发生的行 为” [4]。在不确定性规避指数较强的社会和文化中, 人们倾向努力工作, 有 强烈的紧迫感和进取心。而在不确定性规避指数较弱的社会和文化中, 规则 和原则没那么明确和严格, 人们更乐于冒险和接受新奇陌生的事物, 他们更 有安全感, 比较倾向于放松的生活。

在之前探讨中国的权力距离这一部分中, 提到中华文明是农业文明, “处 肥沃之地, 人们以居住地为根, 衍出 “家本位” , 更导致人们对不确定性和 模糊情境的较强恐惧” [4], 所以中国文化中有安土重迁和落叶归根的说法。 中国的农耕文化表现出 “安稳保守、安而不强、足而不富、和合内倾” [3] 的 特点, 这一特有的农耕文化反映在国家政治文化中, 就是 “求稳定” 和 “维 秩序”。因此, 在中国文化中, 人们对于躲避风险和不确定因素有着非常强 烈的需求, 他们在陌生的环境中容易产生紧张的感觉, 希望尽可能与周围的 人建立一种稳定的关系, 减少未来的不确定因素。

影片开始不久, 高伟同不耐烦地在填母亲给他寄过来的相亲表格, 他的 同性爱人赛门早已经跟自己的父母出了柜, 看到他如此烦恼, 便问他为什么 不向父母坦白自己的性取向。高伟同回答说他已经习惯向父母撒谎了, 而且 他也不知道该怎么向父母解释。晚上接到父母给自己打来的越洋电话时, 高 伟同安慰自己的父亲一定会让他抱上孙子, 不会让他失望的。高伟同一直不 愿意跟父母坦诚自己的性取向, 他担心父母接受不了自己是同性恋的事实, 担心会加重已经患有心脏病和高血压的父亲的病情。在隐瞒事实和规避不确 定性可能会带来的风险之间, 他选择了前者。在影片将要结束的时候, 高伟 同的父亲因病入院, 高伟同无法忍受假结婚给自己的生活带来的后果, 便决 定向母亲坦诚自己的性取向, 并告知母亲其实和顾威威的婚姻是假结婚。母 亲听完非常震惊和悲痛, 特地嘱咐他 “可千万不要告诉你爸呀, 会要他老命 的”。高伟同和母亲都选择不将实情告诉高伟同的父亲, 规避他可能会受刺 激病情加重的风险。影片最后, 高伟同的父亲私下告诉赛门, 他其实懂英语, 并且已经知道自己的儿子是同性恋的事实, 但是他不让赛门告诉自己的妻子 和儿子, 也不让他告诉自己的 “儿媳” 顾威威。他说自己隐瞒这些是为了保 全这个家, 自己的儿子是因为担心他的病情才答应结婚, 这样他才可以有机 会抱孙子。高伟同一家人, 都在为规避风险而隐瞒事实, 可以看出中国文化 中不确定性规避指数相对较高。 


\section{4. 高语境与低语境}

Edward Twitchell Hall 在 1976 年出版的《超越文化》一书中, 提出文化 具有语境性, 将语境分为高语境(High Context)与低语境(Low Context), 并据 两者的不同来分析文化的多样性。而后来的路斯迪格等学者将高语境文化与 低语境文化及交际的特点做了概括, 简单来说, 高语境文化的交际是秘而不 宣, 内隐含蓄, 交际者的面部表情、微妙的手势以及难以言说的情绪等细节 都是丰富的信息符号, 语言不必是主要的信息渠道, 甚至沉默都可以表达思 想与感情。与之相反, 低语境文化的交际是 “大量的信息由显性的语码负载, 隐性的环境传递出相对少量的信息。也就是说, 在低语境文化中的人们, 习 惯借助言语的力量来交际” [5]。低语境文化中的人们居住松散, 人际关系也 相对独立。因为缺乏共同的生活经验, 所以在人际交往过程中, 人们一定要 尽可能地提供详细的背景信息, 而且语言要具体和准确。

Edward Twitchell Hall 将大部分亚洲文化, 比如中国文化, 以及拉美文化、 非洲文化列为高语境文化, 而把美国、德国、瑞士及多数北欧文化列为低语 境文化。

上文中曾经提到中华文明是农业文明, 人们安土重迁, 由于这样的传统 和历史, 人们在一个固定的地方长期生活, 再加上井然有序的生活节奏, 社 会变化的速度非常慢, 幅度也很小, 人们的生活经验以及人际网络也变得单 一化。“在这种彼此相知的社会中, 人们总是对于环境作出相同的回应, 交 际行为成为固定的模式。相应地, 高语境文化中语言表述模糊含蓄, 信息更 多地存在于文化的内涵之中, 大多数信息不必明白地表达出来, 语义通常存 在于语言之外, 人们 “听话听音”, 交际各方既不要求也不被期待提供详细 的语言信息” [6]。所以中文中会有 “只可意会、不可言传” 以及 “此时无声 胜有声” 的说法。

在影片《喜宴》中, 这种高语境文化的交际有非常明显的体现。高伟同 告诉父亲自己并不打算举行中式婚礼以及大宴宾客, 只想按照西方传统在教 堂里简单地举行婚礼时, 高父吃饭的动作突然停了下来, 沉默良久, 眉头紧 锁, 面露愠色, 高母听到后连忙说道人一辈子才结婚一次, 婚姻是终身大事, 在台湾收了亲戚朋友那么多礼金, 结果却不办婚礼, 这样回去该怎么跟人家 交代。听到他们的争执, 高父把筷子用力地往盘子上一放, 说道: “好了! 年轻人长大了, 有他们自己的意见。爱怎么办就怎么办! ”饭没吃完就站起 来离开了。如果只从高父讲的话来分析, 他表面上是赞同和支持自己的儿子 不举办重视婚礼和一切从简。但是, 从他刚开始的沉默、紧锁的眉头和生气 的面部表情, 再到后来用力放筷子以及饭吃一半就离开的动作, 都可以看出 来高父心中的不悦与愤怒, 这一切虽然他没有用语言表达出来, 但是他内心 真实的想法都直接反映在了他的面部表情和肢体语言上, 甚至讲出来的话也 明显看出来是气话, 并不是其本意。影片将近结尾处, 高伟同的同性爱人赛 门得知顾威威有了高的孩子之后, 非常愤怒, 忍不住当着高伟同父母的面与 他激烈地争吵了起来, 高父依然沉默, 一言不发, 面部表情非常阴郁, 但是 胸部起伏剧烈, 可以看出他情绪波动非常大, 并且在强忍愤怒。从高伟同的 
父亲两次表达愤怒的方式上来看, 隐忍, 含蓄且内玫, 两次几乎都没有用任 何语言来直截了当地表达自己内心真实的感受和想法, 皆通过面部表情或者 是肢体动作间接表达出自己的感受。这些充分体现了中国文化中高语境交际 的特点, 表述模糊含蓄, 不习惯讲话直白具体, 主要的信息渠道不再是语言, 沉默可以表达思想与感情, 面部表情也是丰富的信息符号。

\section{5. 时间取向}

时间是无声的语言, 在人际交往中能够传递很多信息。“时间会说话。 它传达的信息清晰又响亮, 而且有时会比有声语言更加直截了当” [7]。时间 取向影响着人们的思维和行动, 对民族性格、思维方式、生活方式和交际行 为等产生决定性影响, 它属于文化的深层结构。因为不同的文化有着不同的 思维方式和价值观, 对时间概念有着不同的理解和认知, 就会产生不同的时 间取向。正如美国人类学家 Edward Twitchell Hall 所说, “各个文化就像拥 有自己的语言一样, 拥有自己的时间语言” [8]。20 世纪 60 年代, 美国人类 学家、哈佛大学教授克拉克洪(Kluckhohn)和斯托特贝克(Strodtbeck)提出六大 价值取向理论, 时间取向理论便是其中之一。该理论根据文化价值观把人类 的时间取向划分为三种: 一是过去取向 (past-oriented), 强调传统和尊重历史。 二是现在取向 (present-oriented), 通常注重短期和眼前。三是未来取向 (future-oriented), 这种社会一般强调变化和长期。

过去时间取向一般主要存在高度重视传统的文化里。中国是文明古国, 拥有灿烂的文化和悠久的历史, 注重保护传统文化。生活在这种文化中的人 们倾向重视过去, 他们崇拜祖先, 尊敬老人, 尊重老师, 重视年龄和经验, 而这些都与过去有关, 时间上的过去取向影响着中国人的行为和思维方式。 在中国社会, 人们做事情通常会考虑这个时期事情以前有没有人做过, 有没 有一些经验和教训可以吸取。汉语中也有 “不听老人言、吃亏在眼前”、“以 史为鉴、可以知兴替、以人为鉴、可以明得失”、“前事不忘、后事之师”、

“老马识途”、“姜还是老的辣” 等种种说法。康有为在发起 “戊戌变法” 之前, 为了实现自己的改良主张, 实行了 “托古改制”, 即把孔子打扮成 “托 古改制” 和 “改制变法” 的祖师爷, 目的是来论证变法的必要性和合理性。 除此之外, 对中国文化有着深刻影响的儒家思想历来重视历史, 比如孔子就 主张 “克己复礼”, 这里的 “礼” 为西周之礼, 以及说自己 “述而不作, 信 而好古”。而且中国人普遍相信老字号的产品, 觉得质量有保障, 并且中国 的影视剧中有很多是关于历史题材, 仍然经久不衰, 历久弥新。

《喜宴》这部影片中, 在高伟同的母亲来到纽约见自己的准儿媳顾威威 时, 为了表达她内心的喜悦以及对顾威威照顾自己儿子的感激之情, 高妈妈 送给了她很多年前自己年轻时从大陆带到台湾的衣服, 并告诉她这种款式和 面料现在已经没有了, 非常珍贵。高伟同的父亲在自己的儿子结婚之前, 在 他面前回忆自己参军的历史, 并且告诉他, 自己的父亲-也就是高伟同的爷爷 写信给他讲, 老家已经回不去了, 让他自己在外面打拼, 努力扎根立足。高 伟同父亲有次在外面看书, 影片给了那本书一个特写, 书是 1992 年发行的《传 记文学》, 封面上标注有 “新发现孙中山日中盟约”、“陆军接管海军始末” 
的字样。孙中山先生于 1925 年去世, 《中日盟约》签署于 1915 年, 距离 1992 年已经过去了半个多世纪, 但是依然有相关内容的探求与报导。除此之外, 高伟同在纽约举办中式婚礼的时候, 中国的亲戚朋友们仍然要 “闹洞房”。 闹洞房是中国由来已久的习俗，据说起源于先秦汉代时期。无论是高伟同母 亲对于旧衣物的珍惜和重视，还是其父亲对于年轻时峥嵘岁月的回想与追忆， 亦或是时隔多年人们对历史的探寻与发现，以及依然保留了几千年的 “闹洞 房”习俗的中式婚礼，无不体现出了中国文化中的过去时间取向。

\section{6. 结语}

本文从霍夫斯塔德文化维度的权力距离和不确定性规避, 以及 Edward Twitchell Hall 的高语境与低语境以及克拉克洪(Kluckhohn)和斯托特贝克 (Strodtbeck)时间取向来分析《喜宴》中的跨文化因素。《喜宴》讲述了成长 在不同时代和不同国度的两代人面对婚姻时的不同态度和想法。以高伟同和 顾威威为代表的年轻一代在美国文化中生活，他们对婚姻和家庭的看法，与 高伟同的父母有很多冲突的地方。年轻一代和年长一代虽然思想和习惯上有 很大差异, 但是只要以接纳和包容的心态来看待和处理跨文化沟通, 就能够 和谐相处。本文从多个方面分析了《喜宴》这部电影，从文化维度到高语境 与低语境, 以及时间取向理论, 对这部电影的分析比较全面。霍夫斯塔德的 文化维度一共有六个方面, 但是本文因篇幅所限, 只分析了其中的权力距离 和不确定性规避两个方面, 如果有其他学者想分析《喜宴》这部电影, 可以 从霍夫斯塔德的文化维度的其他四个方面来研究。

\section{References}

[1] Geert, H. (2005) Cultures and Organizations: Software of the Mind. McGraw-Hill, London.

[2] Geert, H. (1991) Cultures and Organizations: Software of the Mind. McGraw-Hill, New York.

[3] 钱穆. 中华文化导论[M]. 北京: 商务印书馆, 1998.

[4] 宋雯. 从霍夫斯塔德文化维度理论看汉英文化差异[J]. 安徽文学, 2009(6): 75.

[5] 胡超. 高语境与低语境的文化渊源[J]. 宁波大学学报, 2009(4): 51.

[6] 赵胤伶, 曾绪. 高语境文化与低语境文化中的交际差异比较[J]. 西南科技大学学 报, 2009(2): 46 .

[7] Hall, E.T. (1959) The Silent Language. Doubleday \& Company, New York.

[8] Hall, E.T. (1990) Guide du compartement dans les affaires internationals. Seuil, Paris, 36. 


\section{Appendix (Abstract and Keywords in Chinese)}

\section{基于文化维度和高语境与低语境以及时间取向理论来解读电影《喜宴》中的} 跨文化元素

摘要: 荷兰著名学者霍夫斯塔德在《文化的结局》中提出 “文化维度” 的概念, 这一概念一共包括四个方面: 权力距离、不确定性规避、个人主义 与集体主义, 男性气质和女性气质。美国人类学家 Edward Twitchell Hall 在 Beyond Culture 中提出高语境与低语境, 据此来分析文化的多样性。哈佛大学 教授克拉克洪(Kluckhohn)和斯托特贝克(Strodtbeck)提出时间取向理论。《喜 宴》这部电影由著名导演李安拍摄, 讲述了高伟同, 一位定居在美国的同性 恋者, 为了应付从台北而来逼婚的父母, 与非法移民女画家假结婚而展开的 故事。本文将选取霍夫斯塔德文化维度理论的两个方面, 即权力距离和不确 定性规避, 以及高语境与低语境和时间取向理论来分析《喜宴》这部电影中 反映出的跨文化元素。

关键词: 文化维度, 高语境, 低语境, 时间取向 